\title{
Exploring the maturity and development of global communities of practice
}

\author{
Jørgensen, Rasmus; Scarso, Enrico; Kirchner, Kathrin; Edwards, Kasper
}

Published in:

Knowledge and Process Management

Link to article, DOI:

$10.1002 / \mathrm{kpm} .1612$

Publication date:

2019

Document Version

Peer reviewed version

Link back to DTU Orbit

Citation (APA):

Jørgensen, R., Scarso, E., Kirchner, K., \& Edwards, K. (2019). Exploring the maturity and development of global communities of practice. Knowledge and Process Management, 26(4), 321-331.

https://doi.org/10.1002/kpm.1612

\section{General rights}

Copyright and moral rights for the publications made accessible in the public portal are retained by the authors and/or other copyright owners and it is a condition of accessing publications that users recognise and abide by the legal requirements associated with these rights.

- Users may download and print one copy of any publication from the public portal for the purpose of private study or research.

- You may not further distribute the material or use it for any profit-making activity or commercial gain

- You may freely distribute the URL identifying the publication in the public portal

If you believe that this document breaches copyright please contact us providing details, and we will remove access to the work immediately and investigate your claim. 


\title{
Journal of Knowledge and Process Management
}

Title: Exploring the maturity and development of global communities of practice

Rasmus Jørgensen, PhD student; ${ }^{1}$ Enrico Scarso, Professor; ${ }^{2}$ Kathrin Kirchner, PhD, Associate Professor $;^{1}$ and Kasper Edwards, PhD, Senior Researcher ${ }^{1}$

${ }^{1}$ Implementation and Performance Management, DTU Management, Kgs. Lyngby, Denmark

${ }^{2}$ Department of Management and Engineering, University of Padova, Italy

rasmus.jorgensen@gmail.com

Keywords: communities of practice, knowledge sharing, operations, knowledge management, case study

\begin{abstract}
Researchers have studied the development of communities of practice (CoPs) and proposed that they can be divided into five stages of maturity: 1) potential, 2) building, 3) engaged, 4) active and 5) adaptive. However, there is a lack of current case studies exploring CoP development and the link between enablers and maturity stages. This study adds to the CoP field through a case study of an extreme case: 20 global CoPs, developed by an engineering company, which were subjected to the same development initiatives for the past decade. Document analysis and a group interview with key informants form the basis for the study. The findings confirm the validity of the maturity stage model and its usefulness in understanding how a CoP develops over time. The study identifies nine CoP development initiatives at different maturity stages. Four of the initiatives are of particular interest as contemporary contributions to the maturity model of Gongla and Rizzuto (2001): 1) competence as practice as a process support enabler in the potential stage; 2) CoP mentoring as a people behaviour enabler in the engaged stage; 3) continuous management dialogue as a people behaviour enabler in the engaged stage; and 4) virtual community support as an enabling technology in the potential stage.
\end{abstract}

\section{Introduction}

Knowledge is recognised as a key business asset and a competitive resource. Consequently, organisations adopt various knowledge management approaches (Hislop et al., 2018). One approach is communities of practice (CoPs) (Aljuwaiber, 2016; Bolisani \& Scarso, 2014). CoPs facilitate interpersonal knowledge sharing resulting in improvements in work practices and complementing explicit knowledge-sharing approaches (e.g., written guidelines) (Cordery et al., 2015; Wenger et al., 2002). While CoPs were originally associated with autonomous development (Lave \& Wenger, 1991; Orr, 1996), there is mounting evidence that CoPs can be intentionally developed and 
managed through specific enablers (Aljuwaiber, 2016; Chu, 2016; Iaquinto et al., 2011; Jørgensen et al., 2019; Ng \& Ang, 2007).

CoPs thrive under specific circumstances, accentuating the need for managers to understand and consider CoP characteristics and enablers (Alvesson \& Kärreman, 2001; Wenger et al., 2002). One such characteristic is maturity, defined by $\mathrm{CoP}$ participant behaviour and relations with the promoting organisation, and as behaviour and relations change with maturity, so do enablers of $\mathrm{CoP}$ activity (Gongla \& Rizzuto, 2001; Lee et al., 2010). Scholars frequently refer to the maturity model proposed by Gongla \& Rizzuto (2001), according to which CoP maturity progresses through five stages: 1) potential, 2) building, 3) engaged, 4) active and 5) adaptive. Each stage is associated with specific enablers; consequently, CoP development initiatives must fit the maturity stage (Gongla \& Rizzuto, 2001). Despite the widespread use of the maturity concept, there is a lack of contemporary empirical case studies of CoP development through maturity stages (Lee et al., 2010). Furthermore, new information and communications technology (ICT) (e.g., enterprise social networks [ESNs] for knowledge sharing) and increased practitioner experience with CoPs could result in new CoP enablers and approaches (Bolisani \& Scarso, 2014; Sarka \& Ipsen, 2017; Wehner et al., 2017).

Studying an extreme case (Yin, 2017) would enable new insights about CoP enablers and potentially strengthen the causal explanations of intentional $\mathrm{CoP}$ development through maturity stages. This paper does so by analysing the development of 20 global CoPs established simultaneously in 2008 and subjected to the same development initiatives during the last decade by this study's case company, GEC. GEC (whose real name is disguised for reasons of anonymity) has gradually consolidated tools and methods for managing knowledge through CoPs and implemented this in their corporate strategy.

GEC is a global engineering firm specialising in pharmaceutical production. GEC is considered an extreme case because they have successfully developed global CoPs supported by an ESN and no other such cases have been found. By analysing the CoP development initiatives in accordance with the CoP maturity model proposed by Gongla \& Rizzuto (2001), this study aims at validating and extending the model and providing up-to-date recommendations to managers.

The next section discusses the theoretical background of the study. In section 3, the case context is illustrated. In section 4, the research questions are formulated, and the research approach is described. The findings of the analysis are presented in section 5 and subsequently discussed in section 6. The last section is devoted to the conclusion and includes the limitations of the study and suggestions for future research.

\section{Background}

\subsection{Communities of practice}

A CoP is defined as a 'group of people who share a concern, a set of problems, or a passion about a topic, and who deepen their knowledge and expertise in this area by interacting on an ongoing basis' (Wenger et al., 2002). The term was coined in a study underlining the importance of learning 
in the physical and social context of the actual work (Lave \& Wenger, 1991). While some scholars view CoPs as self-organised and autonomous (Gabbay \& le May, 2004; Orr, 1996; Urzelai \& Puig, 2019), others assert that CoPs can be intentionally developed to improve organisational knowledge sharing and collaboration (Aljuwaiber, 2016; Barbour et al., 2018; Cornes et al., 2014; Wenger et al., 2002).

Research has presented empirical evidence that intentionally developed CoPs impact positively on knowledge sharing and practice development (Jørgensen et al., 2019; Wenger et al., 2002). The advantages of CoPs include that past experience is re-used (Cordery et al., 2015), knowledge is shared among practitioners (Chu, 2016), and tasks are standardised (Schenkel \& Teigland, 2008). Furthermore, CoPs have been intentionally developed in a variety of contexts within the last decade (Aljuwaiber, 2016). However, CoPs cannot be completely forced into life as knowledge sharing is inherently voluntary (Amayah, 2013). Organisations must pay careful attention to a CoP's development in order for the participants to engage in rich conversations and thinking together (Pyrko et al., 2017).

CoPs can exist both physically and virtually (Agrifoglio, 2015). According to Schenkel and Teigland (2008), decreased proximity between community members can result in reduced CoP performance; however, other scholars report that online CoPs can improve knowledge and task standardisation (Cordery et al., 2015). This implies that ICT must be chosen to accommodate specific needs (e.g., case context and CoP maturity stage) (Dubé et al., 2006). More specifically, ICT must support member connectivity, equipment and channel multiplicity must be present, and ICT must accommodate specific knowledge codifiability (Nithithanatchinnapat et al., 2016).

\subsection{CoP age and maturity}

Age and maturity are two characteristics of CoPs which will change even if no management initiatives occur; however, it is not certain that a CoP will mature as time passes (Dubé et al., 2006). Because CoP development involves organisational transition, shifting activity level and radical transformation, it is not a smooth linear process (Wenger et al., 2002). Still, CoP development is generally described using linear stage models spanning from the initial development to the time when activity comes to an end. Scholars have proposed several CoP development stage models which to different degrees integrate $\mathrm{CoP}$ characteristics, processes, critical success factors and development initiatives (Agrifoglio, 2015; Dubé et al., 2006; Lee et al., 2010).

Initially, Wenger 1998 proposed a five-stage CoP development model, then modified it in a subsequent work with McDermott and Snyder (Wenger et al., 2002) devoted to how a CoP should be cultivated in which the authors identified the five stages as follows: potential, coalescing, maturing, stewardship and transformation. According to this model, a CoP is initially a loose network which has the potential to increase activity and thus become more important for the organisation. Through increased participant interactions, CoP members start to coalesce into a community with a growing understanding of their shared interests and relevance for one another. The CoP then matures, expressed through an increase in participants and a deeper shared knowledge among them. Then follows a stage in which the CoP assumes active stewardship of 
knowledge and practices which they consciously develop. Finally, the CoP transforms as the shared interests of the participants change.

A five-stage model was introduced by Gongla \& Rizzuto (2001) comprising: 1) potential, 2) building, 3) engaged, 4) active and 5) adaptive stages. Each stage is associated with enablers of CoP activity which organisations can operationalise through intentional $\mathrm{CoP}$ development initiatives. Enablers are categorised into people behaviour (individual, group and organisational behaviour), processes (defined roles and activities for people to perform) and technology (the application of science and ICT to fashion tools, practice knowledge arts, and extract data and information) (Gongla \& Rizzuto, 2001, p. 848). In the potential stage, a nucleus forms comprising individuals with a shared interest, but the individuals have yet to fully realise the commonality. Connection is the primary activity as the individuals locate one another, communicate and form relationships. In the building stage, a community starts to take shape and define itself in terms of "what the community is going to be and how it is going to build and declare its existence' (Gongla \& Rizzuto, 2001, p. 847) and also develop supportive processes and structures. The community members build a common 'understanding of what the community is and what it is not, why it is forming, and how it will function' (Gongla \& Rizzuto, 2001, p. 847). In the engaged stage, the community functions with a common purpose. The community grows in size and complexity, and the structure and processes come into action. Access between community members and access to group knowledge are key functions. 'The community really begins building its capability to leverage its explicit and tacit knowledge' (Gongla \& Rizzuto, 2001, p. 847). In the active stage, a community reflects, analyses and begins to comprehend, define and assess the value for the members and the organisation and 'further extends its membership and builds relationships to other communities'. In this stage, the biggest challenge is to sustain momentum. The community draws on its collective knowledge and collaboratively brings benefits to the organisation. Members define and share the value they bring to the larger organisation. 'Collaboration promotes an understanding throughout the larger organization of the need for and distinct benefit from the community's knowledge and work' (Gongla \& Rizzuto, 2001, p. 847). In the adaptive stage, the community adjusts continuously to create knowledge and to establish the new structures and processes it needs to leverage its knowledge. The community innovates and generates, creating 'new solutions, new offerings, new methods, new processes, and new groups. The community identifies, influences, and even creates trends in its area of expertise' (Gongla \& Rizzuto, 2001, p. 847). Figure 1 summarises the evolution model of Gongla \& Rizzuto (2001).

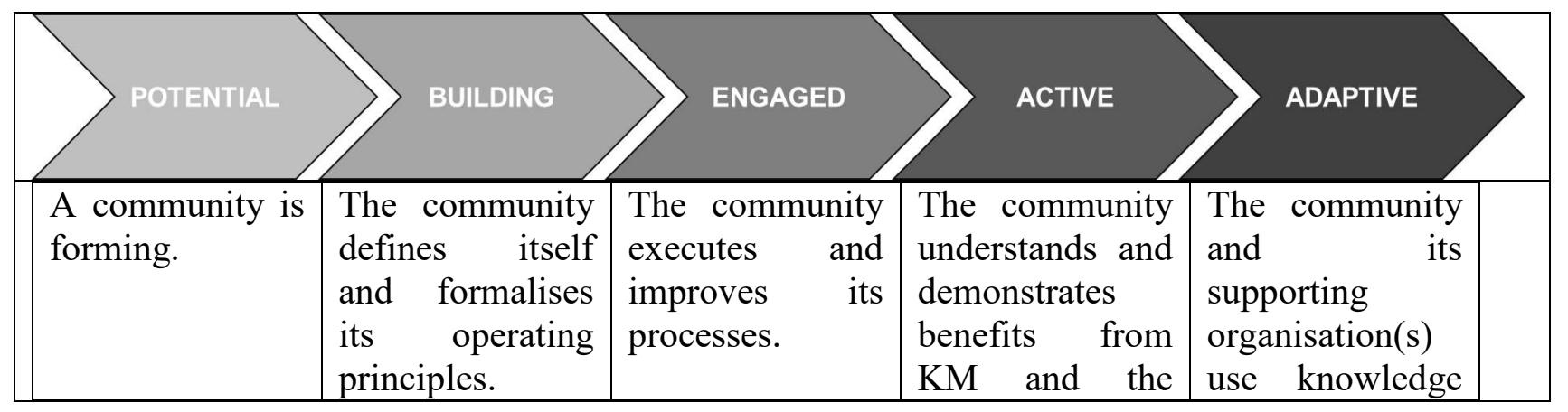




\begin{tabular}{|l|l|l|l|}
\hline & & $\begin{array}{l}\text { collective work for competitive } \\
\text { of the } \\
\text { community. }\end{array}$ & $\begin{array}{l}\text { forvantage. } \\
\text { adval }\end{array}$ \\
\hline
\end{tabular}

Figure 1. Community evolution model definition (Gongla \& Rizzuto, 2001, p. 845).

Based on a critical review and synthesis of what had been previously developed in the literature, Lee et al. (2010) developed a four-stage model defined as a CoP maturity model. The authors proposed and tested the model with the purpose of 'providing a road map for moving from immature, inconsistent activities to mature, disciplined approaches aligned to strategic business imperatives' (Lee et al., 2010, p. 2681). The four stages are: building, growth, adaptive and close. Each stage is linked to several enablers called critical success factors (CSFs) which must be converted into initiatives taken by the organisation for the CoP to move between stages (i.e., increase maturity). The first stage, building, is when 'members come together and recognize their potential, discovering people who already network around the topic, the strength of those relationships, the problems, and the potential of the community for growth' (Lee et al., 2010, p. 2673). The building stage is linked with three CSFs: creating initiative, organising structure and making a rhythm. In the second stage, growth, the 'community is growing up in perspectives scale and internal quality' and the 'community expands new ideas and perspectives and increases the exposure of members' (Lee et al., 2010, p. 2673). This stage is linked with four CSFs: activating knowledge creation, strengthening individual capacity, consolidating membership and becoming a legitimate influential community. In the third stage, adaptive, 'Members' knowledge and best practices are well shared, the knowledge is well adapted in real works, and moreover innovation based on the knowledge is made' (Lee et al., 2010, p. 2674). The adaptive stage is linked with two CSFs: extending human networks and focussing innovation. In the fourth stage, close, the CoP can either decline by members leaving, or it can become a social club and become invalid or transform if the CoP becomes an actual department. Consequently, the fourth stage is linked with two CSFs: declining and transforming. In the conclusions, the authors underline a call for empirical studies of CoP development and maturity stages, which we answer in this paper.

\section{Case context}

GEC is a Danish global engineering company specialising in the pharmaceutical industry with approximately 2000 employees in 15 offices in Europe, China, India and the U.S. GEC expects employees to consult written engineering guidelines when developing customer solutions. Employees should provide feedback or suggest improvements to the guideline owner, which is often a community, and participate in knowledge development discussions. GEC also expects employees to leverage the globally dispersed GEC workforce to resolve problems and find solutions by posting questions online or directly to GEC experts (e.g., through the CoP).

GEC has organised 20 global CoPs, which they refer to as communities of interest (CoIs). At present, 1783 employees are members of at least one community. CoIs have become a central part of the GEC strategy to become a world-leading pharma engineering company with access to the knowledge of experts around the world. CoI participants are voluntary practitioners who interact 
continuously, and the communities define their own tasks, are responsible for stewarding knowledge within GEC, and have a long-term focus. Consequently, the CoIs have the characteristics of CoPs, and this study regards them as such (McDermott \& Archibald, 2010; Wenger et al., 2002). Most of the CoIs' activities currently occur within the ESN Connect. The CoIs were established in 2008 and their activity and impact have been growing steadily since: 2017 saw a $25 \%$ increase in questions asked online (1053 questions), and 146 improvement ideas were implemented (see Figure 2). The red dots indicate the total number of comments on 'Connect'; a comment is typically a contribution to a discussion about a CoP topic.

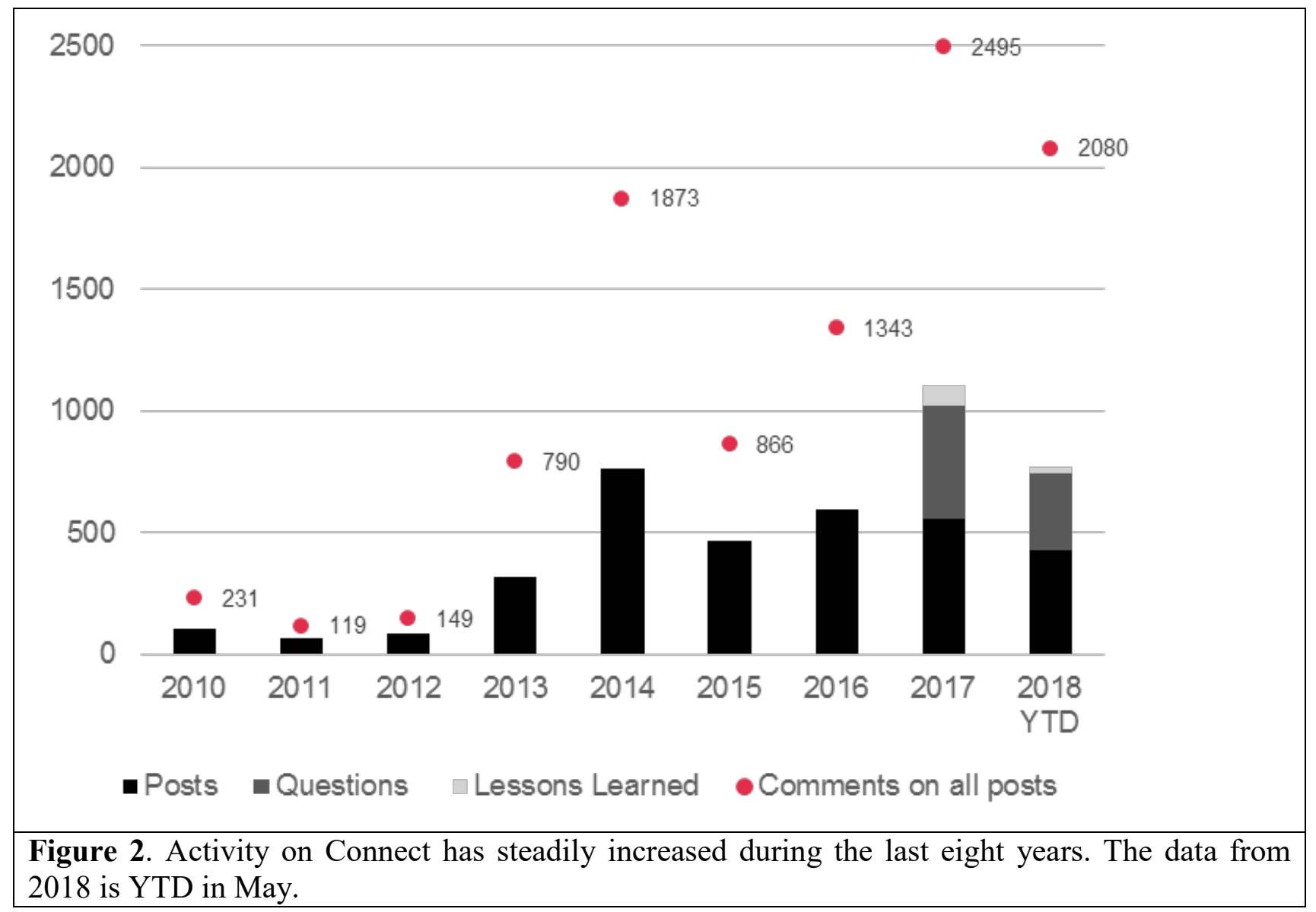

Each of the 20 CoIs represents a competence which has been identified by at least four countries as a core competence. The CoIs are responsible for writing the global engineering standards and implementing best engineering practice derived from projects throughout the world. They also maintain GEC's knowledge base and obtain answers to problems. Several ICT tools, including ESN Connect, a global quality management system (QMS) and other ICT tools such as email support the communities. Figure 3 depicts a Connect feed, which is similar to the feed from other social media platforms, such as LinkedIn and Facebook. Each community has a chairman who is responsible for the CoI and key members' engagement as well as the administrative tasks of meeting invitations, reporting on CoI performance, maintaining a dialogue with the CoI board, and budget management. A CoI has several voluntary key members who are recognised experts in their fields, and they are 
central to developing and sharing knowledge and answering questions. Additionally, any employee can become a CoI member by clicking a button on the CoI Connect page and participate in discussions. The size of a community ranges from 67 to 373 members.

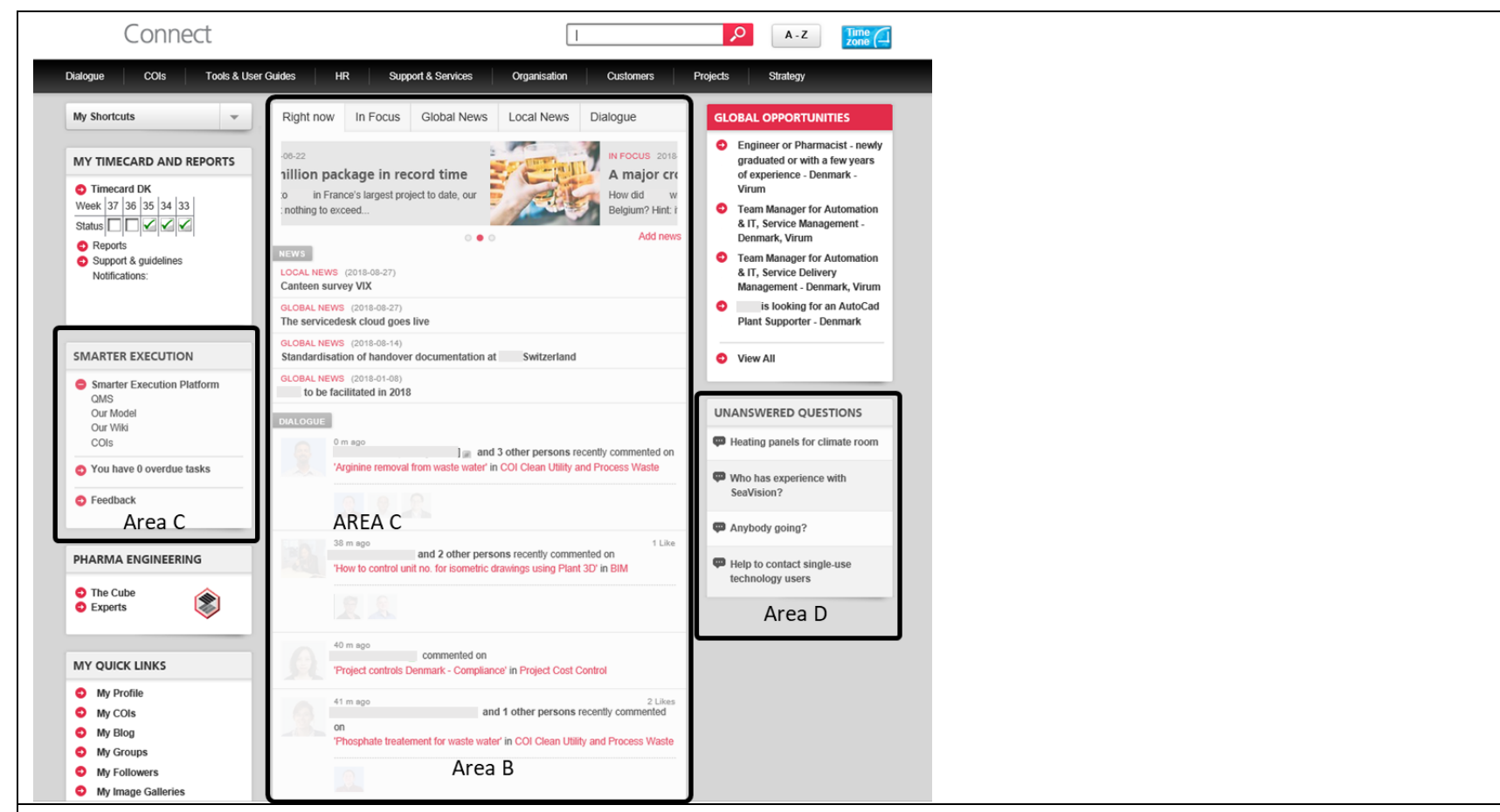

Figure 3. A Connect feed, which shares similarities with other social media feeds such as LinkedIn. Area A is dedicated to unanswered questions posed to CoIs. Area B is the personal feed with discussions, updates and questions from the CoIs of which a participant is a member. Area $\mathrm{C}$ contains links to feedback on content members are responsible for and links to engineering standards, the QMS and guidelines.

The CoIs are governed by a CoI board comprising management representatives from the countries in which GEC operates, and the CoI board is responsible for the COI budget and strategy. The Global Best Practice (GBP) department supports the CoIs, for example, facilitating workshops on CoI development, redirecting questions to CoIs, recruiting chairmen and key members, liaising with top management about CoI resources and implementing and developing ICTs (e.g., Connect).

\section{Study approach}

\subsection{Research questions and method}

This study is framed by the following research questions:

Research question 1 (RQ1): What initiatives support intentionally developed CoPs at the five maturity stages?

Research question 2 (RQ2): How do the initiatives enable CoPs?

The study adopts a case study research strategy with an exploratory character as the purpose is to explore and describe the community development initiatives within the specific case context ( Bryman \& Bell, 2011; Yin, 2017). This is achieved through a mapping of the CoI development 
initiatives taken by the case company followed by explanation building through which causal explanations are proposed through an analyses of the initiatives (Yin, 2017).

The study followed six steps (see Figure 4): Step 1: Data was collected from the case company through a group interview. Step 2: An analysis yielded preliminary results. Step 3: The preliminary results were triangulated through verification (Yin, 2017) with the interview participants, which informed a second analysis (Step 4), which again was verified with interview participants (Step 5). Step 6: The final analysis yielded the study findings.

\begin{tabular}{|c|c|c|c|c|c|c|c|c|c|c|}
\hline $\begin{array}{c}\text { 1. Data } \\
\text { collection } \\
\text { (workshop } \\
\text { and } \\
\text { documents) }\end{array}$ & $\Rightarrow$ & $\begin{array}{c}2 . \\
\text { Preliminary } \\
\text { analysis }\end{array}$ & $\Rightarrow$ & $\begin{array}{l}\text { 3. First } \\
\text { feedback } \\
\text { and } \\
\text { verification } \\
\text { w. GBP }\end{array}$ & $\Rightarrow$ & 4. Analysis & $\Rightarrow$ & $\begin{array}{l}\text { 5. Second } \\
\text { feedback } \\
\text { and } \\
\text { verification } \\
\text { w. GBP }\end{array}$ & $\Rightarrow$ & $\begin{array}{l}\text { 6. Final } \\
\text { Analysis }\end{array}$ \\
\hline
\end{tabular}

Figure 4. The study process.

\subsection{Data collection and analysis}

Data was collected through a joint interview with two GBP employees in May 2018. The CoIs were not studied individually because they were initiated simultaneously and subjected to the same development initiatives. The participants were a community project manager with three years' seniority and the GBP manager with eight years' seniority. The employees were directly responsible for developing the CoI, and thus provided insights from a corporate perspective. The GBP manager's seniority made it possible to build a timeline of initiatives partially based on her firsthand knowledge. Both participants' positions required them to focus on CoI development in GEC and made them highly knowledgeable about the initiatives. The primary author (RJ) facilitated the interview, which lasted for two hours, in which the CoI initiatives were explored from five perspectives: processes, structures, reward, people and strategy (Kates \& Galbraith, 2007). The perspectives were explored successively. The participants' responses were written on a whiteboard and Post-it Notes, which were subsequently photographed for documentation and quotes were documented in written notes (Edwards \& Winkel, 2018). Following the workshops, the GBP manager emailed documents describing the GEC strategy, the community organisation and activity. The preliminary analysis of documents and quotes was conducted collaboratively among the authors, and CoP initiatives were mapped chronologically and described in detail to build a coherent understanding of what GEC has done to develop the CoIs. Following the preliminary analysis, RJ emailed the preliminary results to the workshop participants, who provided feedback on the findings in writing and during a telephone meeting. A new analysis round took place in which the authors linked CoI development initiatives with the five CoP maturity stages and enablers (Gongla \& Rizzuto, 2001). RJ again emailed the results to the workshop participants, and their feedback was collected during a telephone interview. 


\section{Findings: A chronological presentation of CoI development initiatives}

To provide a comprehensive overview of the CoI evolution at GEC, this section presents the development initiatives chronologically. The next section analyses how the initiatives relate to CoP maturity stage and enablers.

The first sign of the CoIs can be traced to 2003, when GEC established the predecessor of the CoIs called technology groups (TGs). A TG consisted of GEC employees (mainly Denmark-based employees at the time) who shared news and asked/answered questions within a certain technological area. TGs were supported by an email application (fundamentally a group e-mail functionality in the e-mail application Lotus Notes), and anyone could sign up to receive emails and reply.

In 2008, the CoI term was introduced in the company. GEC asked all country representatives what competencies they considered relevant, and the competencies which were deemed important by all countries became CoIs. Competencies which were not considered unanimously important became interest groups (IG), which share some of the characteristics of CoIs, but the only support offered to IGs is a Connect page. This transformed all the TGs into either CoIs (20 in total) or IGs (app. 18); thus, GEC formally recognised the CoIs as important for knowledge sharing and collaboration. No CoIs were closed or established after 2008.

In 2008, in order to support the classification and storing of knowledge, GEC introduced the QMS, also called Our Model, and a wiki for storing engineering guidelines called OurWiki. Our model and OurWiki are software solutions for storing, sharing and reading documents, and they are the responsibility of the GEC quality assurance team. At this time, the CoIs and the QMS did not have an official link; however, the CoI members developed knowledge and contributed to updating the documents in Our Model and OurWiki as some CoI members were experts in their field.

In 2011, the CoI structure was developed, defining the roles of chairman, key person and member, and the structure was formally recognised by GEC.

In 2013, the CoIs assumed the responsibility of developing engineering standards stored in OurWiki, which made them formally responsible for the knowledge base of GEC.

In 2014, the CoI Mentor Programme was introduced, resulting in all new employees being assigned a mentor from a community. The CoI mentor helps the new employee become acquainted with the CoI, learn how to apply the engineering standards and how to interact with community members. The new employee participates in a CoI introduction programme which comprises several steps. First, the employee completes an online game serving as an introduction to knowledge management processes and tools at GEC, which includes an introduction to the GEC community. Second, the mentor and the employee have a physical meeting in which the mentor introduces the employee to Connect and trains them in the use of OurModel. The employee is also introduced to the guidelines specific to his/her area of responsibility and is given the task of applying these guidelines in the actual work. Third, at a second meeting with the mentor, the employee must demonstrate and 
explain the application of the engineering guidelines. The employee can then voluntarily decide how to continue the interaction with the CoI and whether membership is appropriate.

In 2016, the CoIs were affirmed as an important resource for GEC's strategy, and the company explicitly linked them with the strategy by relying on the CoIs to facilitate global knowledge sharing. The GEC strategy for 2016-2018 stated that their target was to become a pharma engineering company with local presence leveraging global industry expertise. GEC has two focal points related to knowledge explicitly in their strategy Master core competencies and Activate best practice. Customers also expect GEC to draw on the best people around the world to solve problems and design solutions. A key differentiator for GEC is to have access to experts worldwide and the CoIs are a key factor in realising this, which is explicitly stated in the GEC strategy presentation and on the official company webpage (see Figure 5).

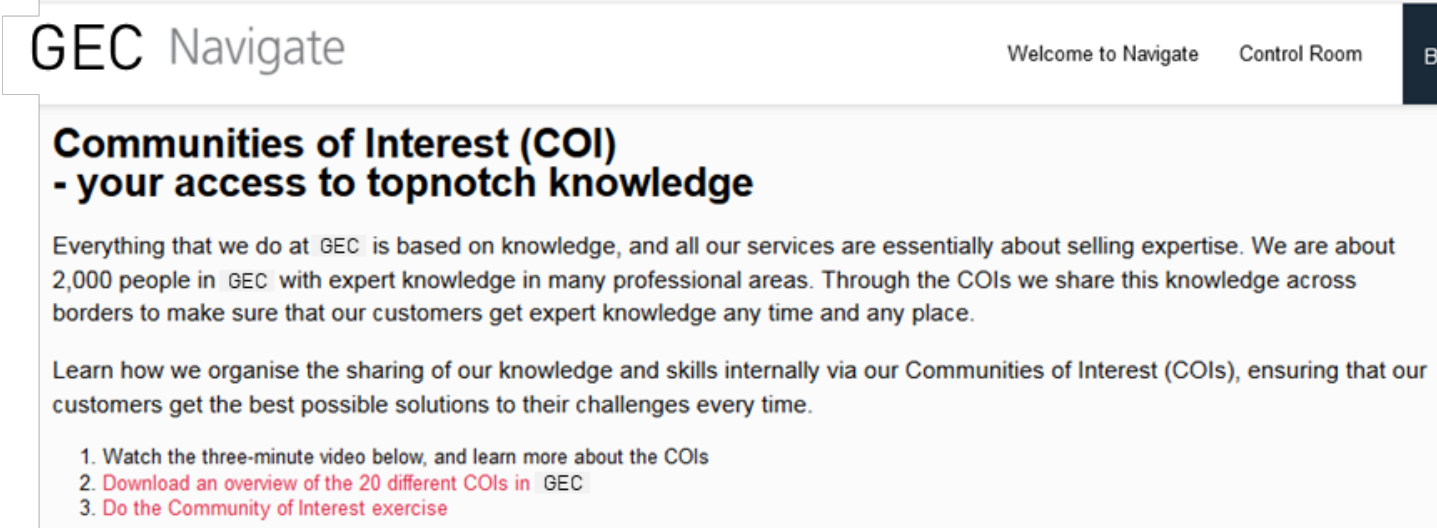

Communities of Interest (COI) - your access to topnotch knowledge

Everything that we do at GEC is based on knowledge, and all our services are essentially about selling expertise. We are about 2,000 people in GEC with expert knowledge in many professional areas. Through the COls we share this knowledge across borders to make sure that our customers get expert knowledge any time and any place.

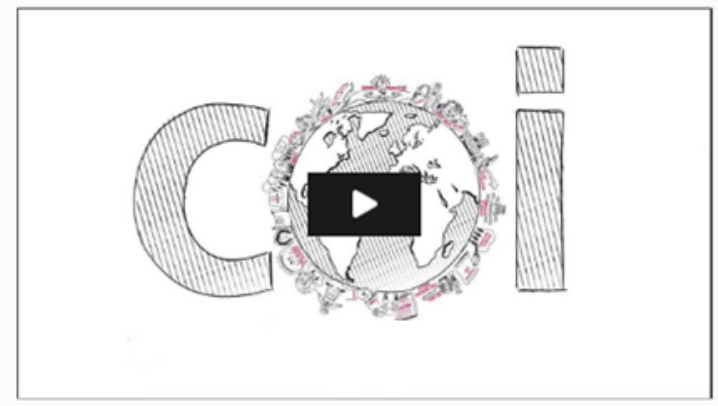

Figure 5. The GEC homepage, which has a section on CoIs and knowledge sharing (image captured 21 June 2019).

Thus, the CoIs are linked to the GEC strategy and described as a key initiative for achieving global knowledge sharing. Consequently, top management have stated the importance of the communities and expressed the business value they bring.

In 2016, a CoI board was established to promote, support and govern the collective work of the communities. The CoI board is made up of 10 management representatives from all countries who assemble twice a year, and includes four members from Denmark (see Figure 6). Occasionally a $\mathrm{CoP}$ key member or specialist is invited to participate. The board is responsible for the budget and strategy and allocates resources to the community and supports specific initiatives. Each of the 
board members are responsible for direct support for one to three CoI chairmen, and a board member is also responsible for supporting engagement among key members from their own country. Each year the board supports the COIs in formulating development plans for the coming year based on what the COI key members deem important (as opposed to formulating plans based on what the top management has defined as important goals).

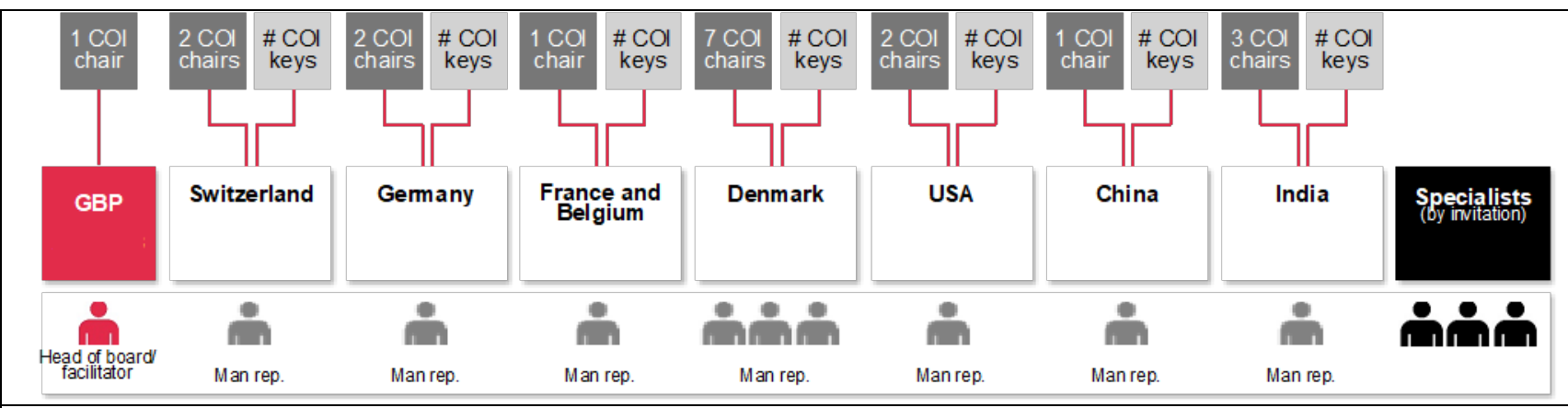

Figure 6. The CoI management board (figure adopted from a private GEC strategy presentation).

In 2016, a lessons learned process was introduced making it mandatory for all GEC projects to include a workshop searching for feedback on engineering standards and experiences which could contribute to GEC's knowledge. The workshop outcomes are relayed to the relevant CoIs, which must process the outcome and provide feedback. The ESP Connect was also introduced in 2016 to support the CoIs' global focus, improving communication between the CoIs and between employees and CoIs.

\section{Analysis and discussion: Development initiatives and maturity stage}

This section analyses the COI development initiatives in accordance with the five-stages model of Gongla \& Rizzuto (2001), describing how people, process and technology are interlinked and enable COIs at a given maturity stage (see Figure 1).

\subsection{Potential stage}

The establishment of TGs was GEC's initial CoP development and marked the beginning of the potential stage as people linked up through TGs, enabled by GEC through the development of email groups. The e-mail groups are pivotal for an engineering company in which employees often work off-site and have few opportunities to interact with each other.

Enablers in the potential stage (Gongla \& Rizzuto, 2001) leveraged by GEC:

- People behaviour: Individuals find one another and link up; organisation provides support to locate individuals;

- Process support: Facilitating bringing individuals together;

- Enabling technology: Electronic messaging systems (email). 


\subsubsection{Discussion}

The self-organised TGs connected people with a common interest in a topic and sharing knowledge. Connecting people voluntarily is compatible with developing CoPs because connecting the right people is a prerequisite for CoP members to think together (Pyrko et al., 2017). The TG members chose their topic (the practice, in CoP terms), and GEC offered enabling technology. With care, this approach can result in CoPs which the management finds relevant to support and employees care to participate in voluntarily, which are two fundamental elements of CoP development (Borzillo, 2009; Jørgensen et al., 2019).

The success of the TGs begs the question, 'Why not leave the CoPs (TGs) alone?' Indeed some studies consider the CoP an emergent phenomenon which is self-organised (Lave \& Wenger, 1991; Orr, 1996; Urzelai \& Puig, 2019), and without initiatives from management the TGs could probably function while some would fade away (Wenger et al., 2002). However, to leverage the potential of CoPs and bring systematic benefit to an organisation, initiatives such as recruiting a stream of new participants, allocating resources, and providing technical support are necessary (Scarso et al., 2009; Wenger et al., 2002).

\subsection{Building stage}

The 'building stage' appears to have been entered into in 2008 when the term 'CoI' was first used and the former TGs were recognised officially by the company, followed by GEC naming specific roles in the CoI in 2011.

In 2011, GEC introduced the OurModel and OurWiki systems for classifying and storing knowledge, and although initially there was no link to the CoIs, the introduction of the systems paved the way for a global knowledge management system linking the CoIs with an explicit knowledge repository in the QMS.

Enablers in the building stage leveraged by GEC (Gongla \& Rizzuto, 2001):

- People behaviour: Share experiences and knowledge; create roles and norms; formal recognition of the community;

- Process support: Classifying and storing knowledge;

- Enabling technology: Common repository; document and library management systems.

\subsubsection{Discussion}

By developing OurWiki, GEC made it possible for the COIs to store their knowledge and share it with all employees and future CoI members. A QMS only covers explicit knowledge; however, the combination of COIs and OurWiki provided GEC with methods suited to both tacit and explicit knowledge sharing (Hansen et al., 1999; Hislop et al., 2018).

The name change from 'technology groups' to 'communities of interest' is a consequence of management's interest in the CoIs and having the CoIs contribute to the organisation. However, labelling something 'CoP' does not result in participants thinking together (Pyrko et al., 2017), and GEC's supplementary CoP development initiatives support this claim. To re-frame the TGs as CoIs, 
GEC used competence as the focus of COI activity (i.e., the shared practice); thus competence became a proxy for practice and developed a CoP. The focus on competence instead of a specific practice is relevant for a knowledge work context and could be applied in the potential stage to connect individuals. The study considers this a key finding and labels it competence as practice.

\subsection{Engaged stage}

GEC initiated the CoI mentor programme to structure and increase outreach to new employees through information and socialisation, and the programme marks the engaged stage. The establishment of the CoI board in 2016 also marks the engaged stage: 'the organisation may set up regular interaction with the community at this stage to keep track of its activities and progress' (Gongla \& Rizzuto, 2001, p. 851).

Enablers in the engaged stage leveraged by GEC (Gongla \& Rizzuto, 2001):

- People behaviour: Outreach to new members; ensuring that the organisation interacts with the community;

- Process support: Socialising new members; ensuring self-governance and self-regulation;

- Enabling technology: No particular technology acted as a CoI enabler in this stage.

\subsubsection{Discussion}

The mentoring of new employees supports continuous recruitment of new participants and plays an important role in sustaining the CoI. The apparent consequence is that employees become knowledgeable about the CoIs and begin to interact with them. Furthermore, the face-to-face approach of the CoI mentor supports the development of trust between the new employee and the experienced community participant, and trust supports knowledge sharing (Amayah, 2013; Usoro et al., 2007). The mentoring could also be understood as an example of legitimate peripheral participation (Lave \& Wenger, 1991). The mentor is the experienced practitioner who interacts with and builds a relationship to the 'newcomer', who thereby learns to be a member of a specific community. The potential drawback is that new employees might not consider participation voluntary but something which is expected by GEC and enforced through face-to-face contact, which would be in stark contrast to the fundamental element of voluntary participation (Jørgensen et al., 2019; Wenger et al., 2002). The CoI mentor must therefore be aware of how new employees are approached and how CoI participation is framed. The study considers this a key finding and labels it CoP mentoring.

Developing the COI board marks a shift from the somewhat self-organised approach to an approach which shares similarities with managing an organisational unit. This could potentially be a threat to the COIs if management does not have a careful approach. In this respect, some authors call for a soft management approach (Alvesson \& Kärreman, 2001). The CoI board established a direct relationship between the COIs and the management who could potentially offer important support to the CoIs , which is underlined as crucial by the literature (Borzillo, 2009). However, faced with too many tasks, budgets and time schedules, the energy and motivation to participate in the CoIs could vanish (Wenger et al., 2002). In GEC, however, the interactions between the CoI board and the CoIs have the character of a continuous dialogue (e.g., soft approach): The board supports the 
CoI through investments (e.g., money for physical meetings, Connect development and other CoI activities) while expecting that the CoI key members and chairman develop, present and execute plans for CoI development. The study considers this a key finding and labels it continuous management dialogue.

\subsection{Active stage}

The active stage is entered in 2016 when the CoIs are defined as a decisive strategic element; thus GEC starts to rely on the CoIs' knowledge to contribute with business value. In the same year the lessons learned process was introduced, thereby integrating the CoIs with the organisational processes and engaging the CoIs in solving problems related to the 'real work' of the organisation., The introduction of 'Connect', also in 2016, meant better support for issue-based discussions online, which is of particular relevance for a workforce dispersed across time and geography and thus with limited opportunities for face-to-face discussions.

Enablers in the active stage leveraged by GEC (Gongla \& Rizzuto, 2001):

- People behaviour: Individuals engage other community members to solve problems and do real work; the organisation begins to rely on the community's knowledge to contribute to business value;

- Process support: Problem-solving and decision-making; integrating with organisational processes;

- Enabling technology: Integration of community technology with the applications and technology of the organisation; collaboration tools, such as for issue-based discussion.

\subsubsection{Discussion}

The GEC decision to explicitly rely on the CoIs to realise company strategy, expressed through numerous channels, underlines GEC's expectations of the CoIs. However, considering that support from management and resource allocation are important enablers for organisational change (Nielsen \& Noblet, 2018) and CoP activity (Fung-Kee-Fung et al., 2013; Jørgensen et al., 2019; Schenkel \& Teigland, 2008), the strategic link could be relevant for the potential or building stage. Indeed, top management sponsorship is considered by scholars crucial to ensuring CoP resource allocation (Bolisani \& Scarso, 2014; Borzillo, 2009; Lesser \& Storck, 2001). However, in the day-to-day resource allocation to $\mathrm{CoI}$ activity, middle management must strike a balance between time spent on billable hours and time spent on non-billable hours such as with CoIs. The role of top management and middle management respectively is an important topic for future studies.

The lessons learned process is evidence for the CoIs ability to handle input from the organisation and not focus only on what interests the members, thus solving problems identified by other GEC employees. Having input flow to the CoI from non-CoI members contributes perspectives which inspire and change the $\mathrm{CoI}$ and counter that the CoIs develop in a direction irrelevant to GEC (Huysman, 2004; Wenger et al., 2002).

The introduction of Connect is proof of the technological development which has taken place since Gongla and Rizzuto (2001) published their maturity-stage model, and today companies would 
probably develop an ESN solution in the potential stage as the enabling technology. Today, companies increasingly adopt ESN (Qi \& Chau, 2018), and communication between employees is faster and more frequent than before. Prior to Connect, GEC relied on e-mail groups. With Connect, more employees have access to information from the CoIs, and shared discussions can more easily take place and cross-CoI knowledge sharing is easier. However, with an ESN such as Connect comes the risk of cognitive overload if too much knowledge is made available, and this risk must be mitigated (Bolisani et al., 2018). The study found no data regarding mitigating actions, although Connect is continuously improved based on feedback from employees. The study considers this a key finding and labels it virtual community support.

\subsection{Adaptive stage}

The study cannot affirm that the CoIs have entered the adaptive stage, in which CoPs perform the fundamental function of new products/markets/businesses innovation and generation of new communities. As conjectured by Gongla \& Rizzuto, few communities will reach this stage, and our case confirms this; however, as our study also confirms, a CoP need not reach the adaptive stage to contribute to a company.

To sum up, the analysis of the history of the GEC communities shows how the company has actively intervened and some specific initiatives have been instrumental and marked the evolutionary CoI stages, as illustrated in Figure 7.

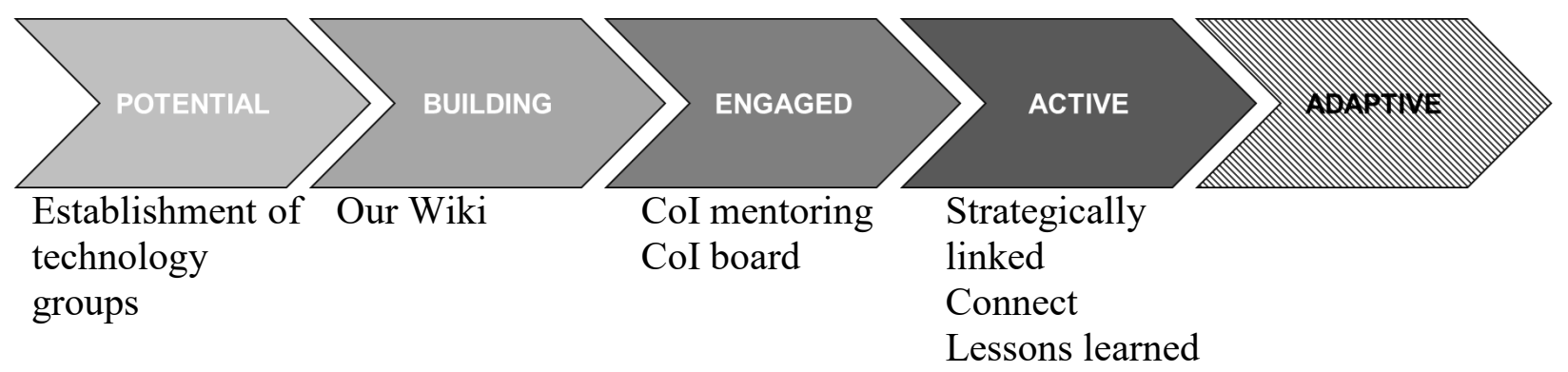

Figure 7. CoI development main initiatives at GEC according to maturity stage. The CoIs did not reach the adaptive stage.

\section{Conclusion}

A $\mathrm{CoP}$ is a knowledge management approach adopted by organisations to leverage knowledge sharing through social interactions. Research has studied CoP development and proposed maturity stage models, but there is a lack of current case studies exploring CoP development and the link between enablers and maturity stage. This study adds to the CoP field through a case study of an extreme case: intentionally developed global CoPs in an engineering company. A group interview with key informants and document analysis informed the analysis of 20 global CoPs (called CoIs) initiated in 2008 and subjected to the same development initiatives for the past decade. Two 
research questions framed the study: (RQ1): What initiatives support intentionally developed CoPs at the five maturity stages? (RQ2): How do the initiatives enable CoPs?

First, the study findings confirm the validity of the Gongla and Rizzuto (2001) model and its usefulness in understanding how a community develops over time. The findings also confirm that not all intentionally developed communities will reach the adaptive stage.

Furthermore, the study identified CoI development initiatives at different maturity stages. Four of the initiatives are of particular interest as contributions to the maturity model of Gongla and Rizzuto (2001): Competence as practice, CoP mentoring, continuous management dialogue, and virtual community support. These findings are relevant for both managers and scholars. Managers can derive suggestions about what initiatives they can undertake to enable CoP development during different maturity stages. From the academic point of view, the study contributes to the debate on the possibility that communities can be intentionally developed, offering further confirmation of this thesis.

This study proposes competence as practice as a process support enabler in the potential stage. In organisations characterised by knowledge work, CoPs can leverage shared interest in a competency instead of a practice or task. The criterion for participating is being knowledgeable within the competency area. Furthermore, organisations can identify competencies through a voting process to which all units can commit resources.

This study proposes $\mathrm{CoP}$ mentoring as a people behaviour enabler in the engaged stage. Assigning a mentor to each new employee introduces the new employee to the CoP and together they train in how to interact with the $\mathrm{CoP}$ and the knowledge it develops. Mentoring supports the continuous recruitment of new participants, and through interactions similar to legitimate peripheral participation (Lave \& Wenger, 1991) new employees train to be CoP participants.

This study proposes continuous management dialogue as a people behaviour enabler in the engaged stage. In a continuous dialogue between $\mathrm{CoP}$ key members and a $\mathrm{CoP}$ board, activity plans are developed and resources allocated. Furthermore, the board supports the CoP in its internal development. Also, a continuous dialogue between the CoP board and the CoP supports congruence between business objectives and $\mathrm{CoP}$ focus.

This study proposes virtual community support as an enabling technology in the potential stage; however, this finding is limited to organisations with a geographically dispersed workforce. The contemporary solution is development of an ESN where employees can communicate, have discussions, and locate each other during the potential stage.

There are several limitations to this study. First, the study concerns a single company operating in a particular sector with specific knowledge needs and capabilities. Future research should consider CoP development initiatives undertaken by companies with different knowledge bases. Second, the study collected data from employees within the GBP department. Future studies should include data from employees to glean an inside perspective on CoP development. Future studies could also study 
individual CoPs or individual levels of participation to analyse how CoP development initiatives have different enabling impacts on CoPs or individuals.

\section{References}

Agrifoglio, R. (2015). Knowledge Preservation Through Community of Practice - Theoretical Issues and Empirical Evidence (1st ed.). New York: Springer International Publishing.

Aljuwaiber, A. (2016). Communities of practice as an initiative for knowledge sharing in business organisations: a literature review. Journal of Knowledge Management, 20(4), 731-748.

Alvesson, M. \& Kärreman, D. (2001). Odd Couple: Making Sense of the Curious Concept of Knowledge Management. Journal of Management Studies, 38(7), 995-1018.

Amayah, A.T. (2013). Determinants of knowledge sharing in a public sector organization. Journal of Knowledge Management, 17(3), 454-471.

Barbour, L., Armstrong, R., Condron, P., \& Palermo, C. (2018). Communities of practice to improve public health outcomes: a systematic review. Journal of Knowledge Management, $22(2), 326-343$.

Bolisani, E. \& Scarso, E. (2014). The place of communities of practice in knowledge management studies: A critical review. Journal of Knowledge Management, 18(2), 366-381.

Bolisani, E., Scarso, E., \& Padova, A. (2018). Cognitive overload in organizational knowledge management: Case study research. Knowledge and Process Management, 25(2), 223-231.

Borzillo, S. (2009). Top management sponsorship to guide communities of practice. Journal of Knowledge Management, 13(3), 60-72.

Bryman, A. \& Bell, E. (2011). Business Research Methods (3rd ed.). New York: Oxford University Press.

Chu, K.W. (2016). Beginning a journey of knowledge management in a secondary school. Journal of Knowledge Management, 20(2), 364-385.

Cordery, J.L., Cripps, E., Gibson, C.B., Soo, C., Kirkman, B.L., \& Mathieu, J.E. (2015). The Operational Impact of Organizational Communities of Practice: A Bayesian Approach to Analyzing Organizational Change. Journal of Management, 41(2), 644-664.

Cornes, M., Manthorpe, J., Hennessy, C., Anderson, S., Clark, M., \& Scanlon, C. (2014). Not just a talking shop: practitioner perspectives on how communities of practice work to improve outcomes for people experiencing multiple exclusion homelessness. Journal of Interprofessional Care, 28(6), 541-546.

Dubé, L., Bourhis, A., \& Jacob, R. (2006). Towards a Typology of Virtual Communities of Practice. Interdisciplinary Journal of Information, Knowledge, and Management, 1(1), 69-93.

Edwards, K., \& Winkel, J. (2018). A method for effect modifier assessment (EMA) in ergonomic 
intervention research. Applied Ergonomics, 72, 113-120.

Fung-Kee-Fung, M., Boushey, R.P., Watters, J., Morash, R., Smylie, J., Morash, C., DeGrasse, C., \& Sundaresan, S. (2013). Piloting a regional collaborative in cancer surgery using a "community of practice" model. Current Oncology, 21(1), 27-34.

Gabbay, J. \& le May, A. (2004). Evidence based guidelines or collectively constructed "mindlines?" Ethnographic study of knowledge management in primary care. British Medical Journal (Clinical Research Edition), 329, 1013.

Gongla, P. \& Rizzuto, C.R. (2001). Evolving communities of practice: IBM Global. IBM Systems Journal, 40(4), 842-862.

Hansen, M.T., Nohria, N., \& Thomas, T. (1999). What's Your Strategy for Managing Knowledge? Harvard Business Review, 12(3), 139-145.

Hislop, D., Bosua, R., \& Helms, R. (2018). Knowledge Management in Organizations: A Critical Introduction (4th ed.). Oxford, UK: Oxford University Press.

Huysman, M. (2004). Communities of practice: facilitating social learning while frustrating organizational learning. In H. Tsoukas \& N. Mylonopoulos (Eds.), Organizations as knowledge systems: knowledge, learning, and dynamic capabilities (pp. 67-85). London: Palgrave Macmillan.

Iaquinto, B., Ison, R., \& Faggian, R. (2011). Creating communities of practice: scoping purposeful design. Journal of Knowledge Management, 15(1), 4-21.

Jørgensen, R., Scarso, E., Edwards, K., \& Ipsen, C. (2019). Communities of Practice in Healthcare: A Framework for Managing Knowledge Sharing in Operations. Knowledge and Process Management, 26(2), 152-162.

Kates, A. \& Galbraith, J.R. (2007). Designing Your Organization: Using the STAR Model to Solve 5 Critical Design Challenges. San Francisco: Jossey-Bass.

Lave, J. \& Wenger, E. (1991). Situated Learning: Legitimate Peripheral Participation (1st ed.). Cambridge, UK: Cambridge University Press.

Lee, J., Suh, E., \& Hong, J. (2010). Expert Systems with Applications A maturity model based CoP evaluation framework: A case study of strategic CoPs in a Korean company. Expert Systems With Applications, 37(3), 2670-2681.

Lesser, E.L. \& Storck, J. (2001). Communities of practice and organizational performance. IBM Systems Journal, 40(4), 831-841.

McDermott, R. \& Archibald, D. (2010). Harnessing Your Staff's Informal Networks. Harvard Business Review, 88(3), 82-89.

Ng, P.T. \& Ang, H.S. (2007). Managing knowledge through communities of practice: the case of the Singapore Police Force. International Journal of Knowledge Management Studies, 1(3/4), $356-367$.

Nielsen, K. \& Noblet, A. (2018). Organizational Interventions for Health and Well-being - A 
Handbookfor Evidence-Based Practice (1st ed.). New York: Routledge.

Nithithanatchinnapat, B., Joseph, T., Joshi, K. D., \& Weiss, M.L. (2016). Organizational communities of practice: Review, analysis, and role of information and communications technologies. Journal of Organizational Computing and Electronic Commerce, 26(4), 307322.

Orr, J.E. (1996). Talking about machines: An ethnography of a modern job. Ithaca, NY: Cornell University Press.

Pyrko, I., Dörfler, V., \& Eden, C. (2017). Thinking together: What makes Communities of Practice work? Human Relations, 70(4), 389-409.

Qi, C. \& Chau, P.Y.K. (2018). Will enterprise social networking systems promote knowledge management and organizational learning? An empirical study. Journal of Organizational Computing and Electronic Commerce, 28(1), 31-57.

Sarka, P. \& Ipsen, C. (2017). Knowledge sharing via social media in software development: a systematic literature review. Knowledge Management Research \& Practice, 15(4), 594-609. doi.org/10.1057/s41275-017-0075-5.

Scarso, E., Bolisani, E., \& Salvador, L. (2009). A systematic framework for analysing the critical success factors of communities of practice. Journal of Knowledge Management, 13(6), 431447.

Schenkel, A. \& Teigland, R. (2008). Improved organizational performance through communities of practice. Journal of Knowledge Management, 12(1), 106-118.

Urzelai, B. \& Puig, F. (2019). Developing international social capital: The role of communities of practice and clustering. International Business Review, 28(2), 209-221.

Usoro, A., Sharratt, M.W. Tsui, E., \& Shekhar, S. (2007). Trust as an antecedent to knowledge sharing in virtual communities of practice. Knowledge Management Research \& Practice, 5(3), 199-212.

Wehner, B., Ritter, C., \& Leist, S. (2017). Enterprise social networks: A literature review and research agenda. Computer Networks, 114, 125-142.

Wenger, E. (1998). Communities of practice: Learning, meaning and identity. Cambridge, UK: Cambridge University Press.

Wenger, E., Snyder, W.M., \& McDermott, R. (2002). Cultivating Communities of Practice: A Guide to Managing Knowledge. Boston, MA: Harvard Business School Press.

Yin, R.K. (2017). Case Study Research and Applications: Design and Methods (6th ed.). Thousand Oaks, CA: SAGE Publications. 